\title{
Digital transformation of public administration in Russia
}

\author{
Viktor Zakharov, Boris Zalivanskiy, Viktor Sapryka and Elena Samokhvalova*
}

Belgorod State University, 308015 Belgorod, Russia

\begin{abstract}
In modern conditions of emergence of a new "digital" picture of the world, the study interest is represented by the changes taking place in the system of public administration in Russia, as well as the main barriers hindering the digital transformation of management practices. To this end, the authors of the article analyzed statistical data for 2019-2021, characterizing the "digital maturity" of domestic authorities, conducted their own sociological study on the problems of digitalization of public administration. The results obtained indicate that, in addition to the insufficient and uneven pace of technological change (in the context of Russian territories), the lack of necessary digital skills among employees and the population, the effectiveness of digital transformation significantly reduces the lack of understanding by civil servants of the value, essence of digital transformation and its tools. In addition, modernization of the state system in the interests of the population is impossible without effective communications "population-government", the construction of which is currently complicated by mutual distrust.
\end{abstract}

\section{Introduction}

The onset of the digital transformation of state institutions was dictated by the fourth industrial revolution, which significantly changed the economic structure and the life of society as a whole. In the new "digital" picture of the world, document-centric systems of public administration that are not focused on the interests and needs of citizens look archaic, stop responding to the needs of the population, lose the ability to regulate and control that necessitated their transformation.

In part, the stage of transition of authorities to digital reality began a long time ago. Since the end of the 90s of the last century, the system of public administration has used the term "electronic government", which, first of all, denoted the introduction into the practice of public administration of an electronic format of interaction, both internal, between structural units, and external, mainly with consumers of public services [1].

However, the current situation requires profound changes in the functioning of the system of state bodies, affecting not only the subsystems of communication and office work, but also revision of existing approaches and methods of administrative activity. In addition, further improvement of efficiency of administrative processes and

\footnotetext{
*Corresponding author: Samokhvalova@bsu.edu.ru
} 
communications with the population becomes impossible without introduction of the intensively developing newest digital technologies. The main advantage obtained as a result of digital transformation, according to many researchers, is provision of high speed of business processes implemented in the organization [2].

The capabilities of technologies such as the Internet of Things (IoT), big data, cloud computing and mobile technologies are significantly accelerating the overall pace of change. For example, entire industries such as the magazine and newspaper business have been transformed and digitized in a very short period of time [3]. In public administration, the competent use of big data will increase the efficiency of forecasting and strategic planning of the socio-economic development of territories, and the IoT will improve the quality of management decisions by tracking indicators and indicators of their performance.

In addition, cloud and online platforms have revolutionized the process and pace of turning an innovative idea into a business [4]. Digital platforms are becoming a new form of functioning of state institutions, while their key role is to create social value, as a result of the effective implementation of a mechanism to meet the needs of citizens.

Therefore, digital transformation, implying a continuous process of multimodal implementation of digital technologies in the design, deployment and operation of public and private sector services, radically changing them, making them personalized, paperless, cashless, eliminating the requirements of physical presence, based on the consensus of the parties, has become a natural stage of development of the system of public administration, including in Russia [5].

\section{Methodology}

The fundamental foundations for digital transformation, including the public administration system, are technological changes, the ability and willingness of employees to implement them [6]. In this case, technological changes shall be understood not only as modernization and creation of an adequate digital infrastructure that provides the possibility of using modern information technologies. It is important to change the management concepts themselves, to actively introduce into management practice design and process approaches, modern methods of "lean production", "design thinking", and etc.

In turn, the readiness and ability of civil servants for digital transformation of management practices is determined by formation of values and meanings of digital service culture in government bodies, understanding the value, essence and skills of using the latest digital technologies (artificial intelligence, blockchain, Internet of things, virtual reality, and etc.).

In addition, a significant restructuring the system in the interests of the population is impossible without participation of the population itself. Therefore, the readiness of the country's inhabitants to interact with the authorities, including through information technology, is one of the significant factors that determine the pace of the transformations being carried out.

The main purpose of this study is to describe the changes taking place within the digital transformation of government bodies in Russia. In order to assess the ongoing technological changes, the authors analyzed the statistical data for 2019-2021, characterizing the "digital maturity" of the domestic public administration system as a whole and its individual regions. To identify the degree of readiness and ability of employees for digital transformation, a secondary analysis of the data of the sociological study "Personnel Policy in the Civil Service: Current Problems and Necessary Changes" was carried out (the main method is semi-structured expert interviews, $\mathrm{N}=15$ ). The obtained results are partly verified by the results of our own sociological study "Digitalization of Public Administration at the Regional Level" conducted in 2020 in two 
regions of the Central Federal District of Russia (the main study method is an expert survey, $\mathrm{N}=104$ ).

\section{Results and Discussion}

In Russia, the main areas of digital transformation of government bodies for the period up to 2024 are outlined in the national program "Digital Economy of the Russian Federation", which includes 6 federal projects, 60 departmental programs, a number of conceptual documents on transition to digital government, such as a Concept for creation and functioning of a national data management system, texts of regional Strategies and digital transformation programs. It is assumed that the end result of the transformations will be a significant improvement in the quality of public administration, due to complete replacement of documents with data, making management decisions based on them, and effective risk assessment.

However, regional authorities with varying degrees of efficiency cope with the tasks set within the framework of digital transformation. This is confirmed by the preliminary results of the assessment of the digital maturity of public administration in the constituent entities of the Russian Federation, carried out in 2021 by the Ministry of Digital Development, Communications and Mass Media of the Russian Federation. According to its results, out of 85 regions of Russia, only 9, mainly the largest, can be classified as "highly mature". The majority of regions (62) have an average level of "digital maturity", while 14 have a low level [7].

The asynchrony of the process of converting the processes of managing the regions of the Russian Federation into digital is due to difference in the dynamics of technological, value-oriented, cultural changes taking place in them.

The technological changes necessary for the effective embedding of public authorities in the "digital" reality include, first of all, development of digital infrastructure and tools (management technologies) [8].

Development of digital infrastructure in the constituent entities of the Russian Federation occurs unevenly under the influence of both territorial characteristics - low rates of computerization, households connecting to the Internet among the aged rural population, in sparsely populated and remote areas, and the technical unpreparedness of organizations, including authorities, to apply new technologies and tools (broadband Internet, cloud services, ERP systems, RFID technologies).

The worst positions in development of digital infrastructure are observed in the Republic of Ingushetia and the Chechen Republic. Note that if in terms of population computerization and Internet connection these regions are approximately at an average level, and their Internet penetration rate in households reaches a high level, then in terms of telephony and related fixed broadband Internet access, they are significantly inferior to the rest of the regions. In the Chechen Republic and Dagestan, organizations use broadband Internet relatively rarely. The best availability of information and communication technologies is in 15 regions of Russia. The Republic of Tatarstan, the Kaliningrad and Tyumen regions, the cities of Moscow and St. Petersburg are among them. Average indicators are observed in 66 entities of the Russian Federation [9].

Another important component of technological change is the ability of authorities to work with data. Domestic government bodies are still characterized by problems of collecting, storing, analyzing and recording data, inconsistency and low quality of government data (poor compliance with requirements, such as consistency, completeness, reliability, relevance, and etc.). This is confirmed by the data of the Ministry of Economic Development of the Russian Federation, according to which, since 2018, there has been a decline in the activity of publishers for placement of new data sets, and previously posted 
data sets are not updated in time. If in 2017 the authorities published 8,219 sets for the first time on the open data portal, then in 2020 there were only 210 sets, while more than $44 \%$ of the data for 2021 turned out to be irrelevant [10].

Inventory of administrative processes, their algorithms, reengineering using design and process approaches, methods of "lean production", "design thinking", and etc. is also a prerequisite for the digital transformation of control systems. The domestic system of public administration is characterized by insufficient awareness of employees about the essence of "new approaches to management" and their weak application, including due to the lack of methodological support from the federal center in the process of implementing regional projects on the digital economy, a low level of interaction between federal and regional authorities of the Russian Federation, as well as the fact that not all technologies that ensure development of the digital economy, for example, blockchain, unmanned vehicles, are enshrined in law.

The next important condition for the digital evolution of government bodies is the willingness and ability of civil servants to implement the necessary changes [11]. In domestic practice, this is often hindered by their lack of understanding of the main ideas of the transformations being carried out, the mission of their own units. For example, as a result of the author's study, it turned out that less than a third of the polled civil servants (27 $\%$ ) fully support the idea of creating an "Electronic Government" in Russia, despite the fact that the need to develop its elements was declared 19 years ago (in 2002 year in the federal target program "Electronic Russia" (2002-2010). For the sake of completeness, we note that almost every fourth (23\%) found it difficult to answer the corresponding question, and the remaining percentages were distributed among those who rather support introduction of this concept into management practice $(46 \%)$ and rather do not support it (4\%) [12]. In addition, regional authorities experience an acute shortage of personnel with the knowledge and skills necessary to carry out such transformations [13].

Involvement of the population in management processes, on the one hand, is negatively affected by the insufficient degree of adaptation of digital technologies, especially in remote, agrarian regions. Wherein, there is also an insufficient "digital demand" due to the lack of digital skills and competencies among the population. According to the data presented in the collection "Indicators of the Digital Economy: 2021", in 2020, among the residents of our country aged 15 to 72 years, only almost every fourth $(26.1 \%)$ had digital skills of the basic level, only every eighth (12.1\%) - above the basic level, while a low level of digital skills is typical for $40.1 \%$ of the Russian residents. For completeness, we point out that the remaining percentages were distributed between those who did not use the Internet for a long time (three months) $-20.0 \%$ and those who, according to researchers, lack digital skills $-1.6 \%$. Moreover, the dynamics of these indicators compared to 2019 is insignificant and does not exceed $2.5 \%$ [9:163].

As part of the methodology for this study, the ability to send e-mail with attachments was examined, among other skills. It turned out that only $42.2 \%$ of Russians have this skill (and with a large difference between the urban and rural population, $47.1 \%$ among those who live in the city versus $27.4 \%$ among rural residents). The share of Russians who can work with a text editor, copy or move a file, transfer a file between a computer and peripheral devices is even lower (40\%,38\% and $27 \%$, respectively) [9:164].

It is important to emphasize that optimization of administrative processes in public administration shall be carried out in the interests of the end consumer - society. According to the authors, one of the main barriers preventing an increase in the efficiency of public administration is the lack of effective communication between representatives of the authorities and the population, primarily due to mutual distrust of the authorities and the public, stereotypes formed as in relation to the authorities - a group of people striving exclusively for their own well-being and in relation to the population - as a disunited, 
passive and incompetent masses. As for the interest of the authorities in using feedback to increase the customer-centricity, in practice, the authorities themselves often do not take seriously the idea of the need to optimize their own activities based on requests from citizens on specialized platforms.

This is due, firstly, to the lack of awareness of civil servants about such services. As follows from the results of the author's expert study, almost every eleventh civil servant (9 $\%$ ) does not know anything about online platforms created in the region for communication with the population, and every third (32\%) has heard something about them. Only $23 \%$ use such a tool. For the sake of completeness, we note that the remaining percentages were distributed between those who "are registered but do not use the platform for feedback from the population" and those who are "aware but not registered" (18\% each in both cases) [12].

Secondly, in a number of cases there is an attitude on the part of government officials to those who address them as "complainants" interfering with the current functioning. This is partly due to the facts of "consumer extremism" - appeals to such portals of people who pursue the sole purpose of increasing their own popularity and social significance. On the other hand, the work of officials and relevant services with electronic appeals often becomes formal and does not have as its goal actual interaction with citizens, and sometimes there are not only unsubscriptions in the responses, but also cases of imitation of activities using graphic editors. Some experts also point to the difference in approaches to messages-appeals of citizens in federal and regional authorities, calling it the main problem of the current system of working with the population, leading to a situation of mutual distrust of local authorities and the public.

\section{Conclusion}

Management of the socio-economic development of territories in the context of a new "digital" picture of the world becomes impossible without digital transformation of functioning state institutions. In Russia, the main barriers to the ongoing transformations are the underdevelopment of the digital infrastructure in certain regions, the lack of formation of the values and meanings of the digital service culture in government bodies, a lack of understanding of the value, essence and weak use of the latest digital technologies by public authorities (artificial intelligence, blockchain, Internet of Things, and virtual reality, and etc.) and management approaches and methods; problems with quality, algorithms for collecting, storing and using data and designing automated information systems with their use; lack of the necessary digital skills among the population; an acute shortage of personnel with the knowledge and skills required for digital transformation.

The situation is aggravated by the lack of effective communications between representatives of the authorities and the population, due to mutual distrust. As a result, we risk finding ourselves in a situation where the system is reforming itself, automating processes that are not optimal from the consumer's point of view and getting "digital bureaucracy" and "digital chaos" instead of a customer-centric digital management system.

\section{Acknowledgments}

The article was prepared with the support of the Grant of the President of the Russian Federation of the Russian Federation for state support of young Russian scientists - Doctors of Science MD-578.2020.6 "Socio-Cultural Threats to the Transformation of Civilizational Fronts in the Post-Soviet Chronotope". 


\section{References}

1. M. Yu. Pavlyutenkova, Electronic government vs digital government in the context of digital transformation, Monitoring of Public Opinion: Economic and Social Changes, 5, 120-135 (2019). Access mode: https://doi.org/10.14515/monitoring.2019.5.07

2. S. Nadkarni, R. Prügl, Digital transformation: a review, synthesis and opportunities for future research, Management Review Quarterly, 71, 233-341 (2021)

3. J. Karimi, Z. Walter, The role of dynamic capabilities in responding to digital disruption: a factor-based study of the newspaper industry, J Manag Inf Syst, 32(1), 39-81 (2015)

4. K. Vey, T. Fandel-Meyer, J.S. Zipp, C. Schneider, Learning and development in times of digital transformation: facilitating a culture of change and innovation, Int $\mathrm{J} \mathrm{Adv}$ Corp Learn, 10 (1), 22-32 (2017)

5. Digital transformation and the role of enterprise architecture, International Telecommunication Union (2019). Access mode: https://www.itu.int/dms_pub/itud/opb/str/D-STR-DIG_TRANSF-2019-PDF-E.pdf

6. D. Cetindamar, B. Abedin and K. Shirahada, The Role of Employees in Digital Transformation: A Preliminary Study on How Employees' Digital Literacy Impacts Use of Digital Technologies, IEEE Transactions on Engineering Management (2021). Access mode: http://doi.org/10.1109/TEM.2021.3087724

7. Gubernatoram vystavili cifry: predstavlen rejting «cifrovoj zrelosti» regionov (2021). Access mode: https://www.kommersant.ru/doc/4938764

8. T. Kramin, A. Klimanova, Development of Digital Infrastructure in the Russian Regions, Terra Economicus, 17(2), 60-76 (2019). Access mode: http://doi.org/10.23683/20736606-2019-17-2-60-76

9. Indikatory cifrovoj ekonomiki: statisticheskij sbornik, Nac. issled. un-t «Vysshaya shkola ekonomiki» (2021)

10. Otkrytyj dajdzhest PRO dannye (2021). Access mode: https://www.economy.gov.ru/material/file/f8e7119514ee3e6c1dc13c35aa29ff37/open data.pdf

11. H. Dulkadiroglu, Rethinking of The Education for Civil Servants in The Digital Age, Amme Idaresi Dergisi (2019)

12. V. V. Zotov, V. M. Zaharov, V. A. Capryka, A. I. Alekseenko, A. V. Gubanov, K. A. Komkov, A. V. Pastyuk, L. V. SHmigirilova, Publichnoe upravlenie v cifrovom obshchestve: $k$ novomu obshchestvennomu dogovoru: monografiya (2021)

13. S. V. Bajteryakov, A. V. Baryshnikova, V. K. Kopytok, A. Filippova, D. O. SHubina, Kadrovaya politika na gossluzhbe: tekushchie problemy $i$ neobhodimye izmeneniya, Schetnaya palata Rossijskoj Federacii (2021) 